\title{
Examination of Treatment Methods for a PEDOT:PSS Transparent Conductive Film Produced Using an Inkjet Method
}

\author{
Atsushi Nitta1 ${ }^{*}$, Yuki Imamura², Kazuya Kawahara ${ }^{2}$, Kazuhiro Takeda ${ }^{3}$ \\ ${ }^{1}$ Department of Electronic Control Engineering, National Institute of Technology, Kagoshima College, Kirishima, Japan \\ ${ }^{2}$ Advanced Mechanical and Electronic Systems Engineering, National Institute of Technology, Kagoshima College, \\ Kirishima, Japan \\ ${ }^{3}$ Department of Information Engineering, National Institute of Technology, Kagoshima College, Kirishima, Japan \\ Email: *nitta@kagoshima-ct.ac.jp
}

How to cite this paper: Nitta, A., Imamura, Y., Kawahara, K. and Takeda, K. (2017) Examination of Treatment Methods for a PEDOT:PSS Transparent Conductive Film Produced Using an Inkjet Method. Advances in Materials Physics and Chemistry, 7, 311-322.

https://doi.org/10.4236/ampc.2017.78024

Received: June 29, 2017

Accepted: July 24, 2017

Published: July 27, 2017

Copyright (c) 2017 by authors and Scientific Research Publishing Inc. This work is licensed under the Creative Commons Attribution International License (CC BY 4.0).

http://creativecommons.org/licenses/by/4.0/

\begin{abstract}
Flexible devices manufactured using printed electronics have attracted the attention of many researchers. A high-performance transparent conductive film exhibiting high flexibility and elasticity is expected to be developed because of its need for the creation of flexible devices. An indium tin oxide (ITO) thin film, which has generally been used, has weaknesses such as fragility to bending stress and depletion of the resource. This study focused on poly (3, 4-ethylenedioxythiophene)/poly (styrenesulfonate) (PEDOT:PSS), a conductive polymer material, and examined improvement in the resistivity and transmittance of the transparent conductive film produced using an inkjet method. The present study improved the electrical and optical characteristics of the thin film by examining the annealing temperature between printing operations and the application method of a polar solvent. As a result, the resistivity and transmittance of a PEDOT:PSS thin film were $1.49 \times 10^{-3} \Omega \cdot \mathrm{cm}$ and $89.2 \%$, respectively. This film was obtained by annealing at $90^{\circ} \mathrm{C}$ for $30 \mathrm{~min}$ and applying a polar solvent, using an inkjet printer, between printing operations. The printing was performed three times.
\end{abstract}

\section{Keywords}

PEDOT:PSS, Inkjet Printing, Transparent Conductive Film, Flexible Devices

\section{Introduction}

Currently, ITO thin film is used as a standard material for transparent electrodes in electronic devices such as solar cells and displays [1] [2]. However, because an 
ITO thin film contains indium, a rare metal, depletion and increased price of the resource have become issues. Therefore, materials that can be substituted for ITO have been actively studied [3]-[8]. Since ITO thin films are produced using the sputtering method and a dry process, a material and a method which can form a thin film using a wet process, which has a higher production efficiency than that of the dry process, are required. By overcoming these weaknesses and developing a material that can be a substitute for ITO, for the creation of transparent conductive films, inexpensive devices can be stably manufactured.

By analyzing the latest research on flexible electronic devices, it can be determined that the development of a flexible transparent conductive film is urgently required because ITO thin films show fragility to bending stress. To this end, various materials such as organic materials, metallic nanoparticles, carbon nanotubes (CNTs) and oxide-based materials (including zinc oxide), have been studied [9] [10] [11] [12] [13]. Organic materials are noteworthy because a transparent conductive film can be formed using simple processes such as printing and coating [14] [15] [16]. Since organic materials possess excellent flexibility and elasticity, they are suitable for flexible displays and thin-film solar cells [17] [18].

Recently, there has been a significant increase of studies conducted on flexible devices manufactured by printed electronics [19] [20] [21] [22]. By using printing technologies for device manufacturing, complicated circuits can be easily formed, and the apparatus used for manufacturing a device can be made smaller and the cost of manufacturing a device can be reduced.

If a practical, transparent conductive film can be produced using a simple and inexpensive method, such as a printing method, not only electrodes, but also flexible devices can be manufactured using only printing.

However, to use printing technologies, a material must be prepared in the form of ink, the prepared ink must be optimized, and the surface of the film must be even during printing. Moreover, the performance of organic, transparent conductive films must be improved; otherwise, the films cannot be practically used.

Because of these necessary characteristics, this study focused on PEDOT:PSS, an organic electroconductive material exhibiting high flexibility and conductivity, as a substitute for ITO. The aim was to produce a cheap and flexible organic transparent conductive film by forming the film on a plastic-film substrate using an inkjet printer.

In previous studies, it has been revealed that cleaning of the plastic-film substrate with $\mathrm{UV} / \mathrm{O}_{3}$, annealing of the film after it was deposited on the substrate and dipping of the film into a polar solvent were useful to improving the characteristics of the thin film [23] [24]. In the present study, the effects of the removal of a polar solvent by annealing each time after a layer was printed, the changes in the surface state of the film due to the aggregates of PEDOT:PSS particles and the differences in the homogenization of the film surface, according to 
the application method of a polar solvent after annealing, on the improvement in the characteristics of the thin film were examined.

\section{Experimental}

\subsection{Ink Material for a Transparent Conductive Film}

In the present study, CLEVIOS (Clevios ${ }^{\mathrm{TM}}$ PH500) was used as PEDOT:PSS. CLEVIOS PH500 possesses excellent conductivity, permeability, and flexibility. Since the mechanical flexibility of CLEVIOS PH500 is high, it can be used as a material for printed electronics. Figure 1 shows the molecular structure of PEDOT:PSS, and Table 1 shows its physical properties. By adding an additive to PEDOT:PSS, the characteristics of the obtained thin film can be improved. By adding a low-boiling point solvent to PEDOT:PSS, the surface tension of ink is reduced and the wettability of the substrate is improved. When a high-boiling point solvent is added, the secondary doping effect on PEDOT is exerted and conductivity is improved due to the coupling of conductive regions [25]. It was reported that when ethylene glycol, a high-boiling point solvent, was added, insulative PSS was removed, and a conductive region consisting of conductive PEDOT was formed [26]. Like a previous study, the ink composition of PEDOT: PSS:ethanol:ethylene glycol $=70: 20: 10 \mathrm{wt} \%$ was adopted in the present study [24].

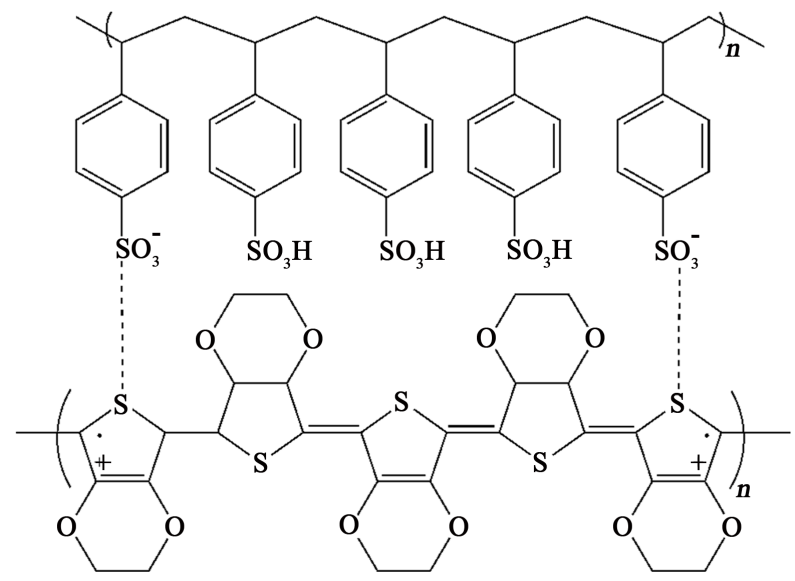

Figure 1. The molecular structure of the PEDOT:PSS.

Table 1. Material properties of the PEDOT:PSS

\begin{tabular}{ccc}
\hline & Typical values & SI unit \\
\hline PEDOT:PSS ratio & $1: 2.5$ & $\mathrm{w} / \mathrm{w}$ \\
Viscosity at $20^{\circ} \mathrm{C}$ & 25 & $\mathrm{mPa}$ \\
$\mathrm{pH}$ at $20^{\circ} \mathrm{C}$ & $1.5-2.5$ & - \\
Density at $20^{\circ} \mathrm{C}$ & 1 & $\mathrm{~g} / \mathrm{cm}^{3}$ \\
Average particle size & 30 & $\mathrm{~nm}$ \\
Bolling Point & approx 100 & ${ }^{\circ} \mathrm{C}$ \\
\hline
\end{tabular}




\subsection{Production and Evaluation of a Thin Film}

To produce a PEDOT:PSS thin film, a piezo-type, pigment-based, inkjet printer (PX-105; Seiko Epson CO.) was used. During printing, the printer was set to [Inkjet paper, Best quality]. For the printing pattern of the PEDOT:PSS thin film, $40 \mathrm{~mm}$ (length) $\times 15 \mathrm{~mm}$ (width) was adopted. A heat-resistant, transparent film possessing excellent transparency, heat resistance, and chemical resistance (Teonex Q65-FA; Teijin DuPont Films Co., Ltd.) was used as the substrate. The surface of the substrate, before film formation, was cleaned using a $\mathrm{UV} / \mathrm{O}_{3}$ cleaning and modifying apparatus (ASM401N; Asumi Giken, Ltd.). For the conditions of $\mathrm{UV} / \mathrm{O}_{3}$ cleaning, the UV radiation distance was $30 \mathrm{~mm}$, the output of a low-pressure mercury lamp was $40 \mathrm{~W}$, and the cleaning time was $20 \mathrm{~min}$. Like a previous study, PEDOT:PSS thin films were formed by printing two to four times [24]. To evaporate the additives that remained in the thin film as impurities after it was formed and adversely affected the conductivity, the thin film was annealed for $30 \mathrm{~min}$ after each time a layer was printed and for $60 \mathrm{~min}$ after the entire printing process was completed, using a constant-temperature drying oven (EOP-300B; As One Co., Ltd.). Ethylene glycol was used as a polar solvent. The thickness of the produced PEDOT:PSS thin film was measured using a stylus-type surface roughness tester (NanoMap-PS; AEP Technology Co.). The resistivity was measured using a digital multimeter(VOAC7521H; Iwatsu Electric Co., Ltd.). The transmittance was measured using a spectrophotometer (U-3900; Hitachi High-Technologies Co.). The surface state of the thin film was observed and its roughness was measured using a microscope (VHX-1000; KeyenceCo., Ltd.) and an atomic force microscope (NaioAFM; Nanosurf Co.).

\section{Results and Discussion}

\subsection{Ink Material for a Transparent Conductive Film}

Annealing is required after each time of printing. Annealing can remove ethanol which decreases conductivity. Unlike with other film formation methods such as the spin coating and roll-to-roll methods, the viscosity of ink affects the ejection of the ink used during the inkjet method. Although the viscosity of ink used for an inkjet printer is generally $5-15 \mathrm{mPa}$-s, the viscosity of PEDOT:PSS (CLEVIOS PH 500) is $25 \mathrm{mPa}$-s. Therefore, the viscosity of PEDOT:PSS was decreased by adding ethanol. However, if ethanol remains on a thin film after it is formed, its conductivity will decrease. Therefore, annealing is required. In previous studies, annealing was performed at $80^{\circ} \mathrm{C}, 100^{\circ} \mathrm{C}$, and $150^{\circ} \mathrm{C}$. The best thin film characteristics were obtained at $100^{\circ} \mathrm{C}$ [23]. In the present study, the annealing temperatures used after each time a layer was printed were changed to $80^{\circ} \mathrm{C}, 90^{\circ} \mathrm{C}$, and $100^{\circ} \mathrm{C}$. Figure 2 shows changes in the resistivity according to the annealing temperature and the number of printing times. The resistivity was lowest at $90^{\circ} \mathrm{C}$ when the number of printing times was three. When the number of printing times was four, the resistivity increased at each annealing temperature. The interface of the thin film increased with the number of printing times. 


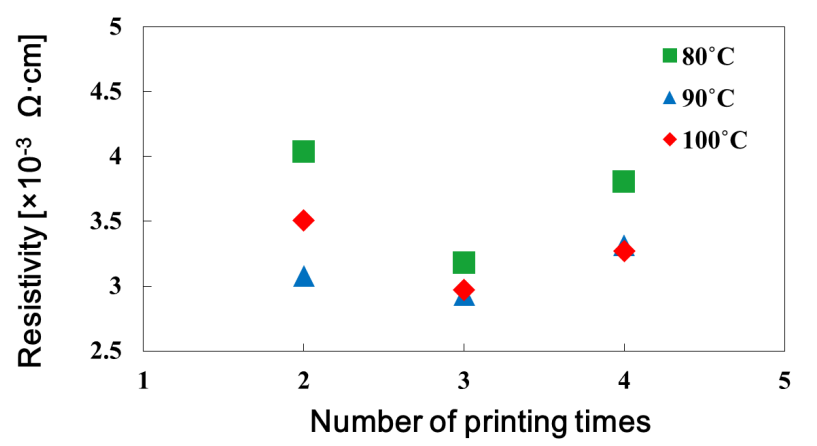

Figure 2. Resistivity as a function of annealing temperature and the number of printing times.

The increase in the interface has the great influence on resistivity. Table 2 shows differences in the thin film thickness, according to the annealing temperature, when the number of printing times was three. The thin film thickness was thinner when the annealing temperature was $100^{\circ} \mathrm{C}$ compared to when the annealing temperatures were $80^{\circ} \mathrm{C}$ and $90^{\circ} \mathrm{C}$. Therefore, the thin film was revealed to have evaporated because the boiling point of PEDOT:PSS is approximately $100^{\circ} \mathrm{C}$. If PEDOT:PSS evaporates after a thin film is formed, the thin film thickness is difficult to control. Figure 3 shows changes in the visible light transmittance according to the annealing temperature and the number of printing times. Transmittance was measured at the wavelength of $550 \mathrm{~nm}$. The visible light transmittance was highest when the annealing temperature was $100^{\circ} \mathrm{C}$. This is probably due to the decrease in film thickness. Figure 4 shows images of the surfaces of the PEDOT:PSS thin films, observed using a microscope. In this figure, Figure 4(a) shows that because the aggregation of the thin film was large when the annealing temperature was $80^{\circ} \mathrm{C}$, a state in which the thin film seemed to be blurry was observed. Therefore, it was revealed that ethanol remained on the film, it was not sufficiently removed. Also, in this figure, Figure 4(b) and Figure 4(c) show that because the aggregation state of the thin film did not change when the annealing temperatures were $90^{\circ} \mathrm{C}$ and $100^{\circ} \mathrm{C}$, respectively. In these thin films, ethanol was sufficiently removed. When difficulty in controlling the film thickness due to the residence of ethanol and the evaporation of PEDOT:PSS was taken into consideration, the optimal value of the annealing temperature was $90^{\circ} \mathrm{C}$.

\subsection{Examination of the Application Method of a Polar Solvent}

Drying a PEDOT:PSS thin film again, after dipping it into a polar solvent, was reported to facilitate the arrangement of PEDOT molecules, resulting in improvement of the conductivity of the PEDOT:PSS thin film [27]. In a previous study, by spraying the polar solvent on a PEDOT:PSS thin film after each time a layer was printed, the characteristics of the PEDOT:PSS thin film were improved in terms of resistivity and transmittance [24]. However, there was a limitation in uniformly applying a polar solvent by artificially spraying it. Therefore, the aim 


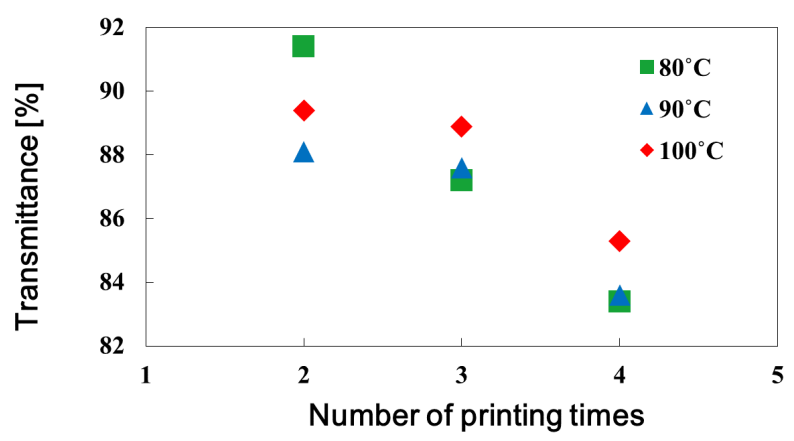

Figure 3. Transmittance as a function of annealing temperature and the number of printing times.

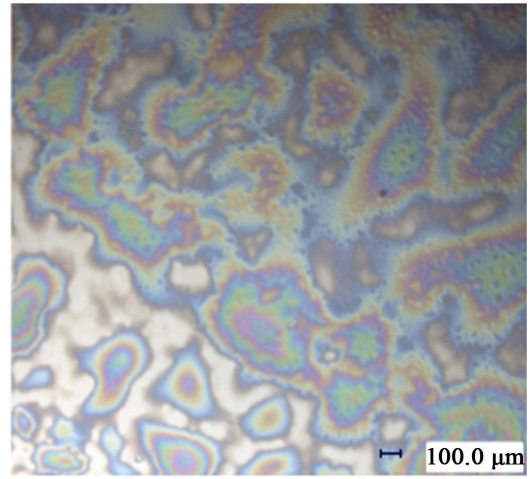

(a)

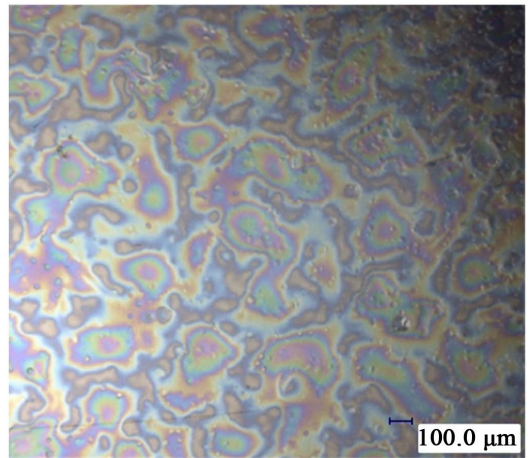

(b)

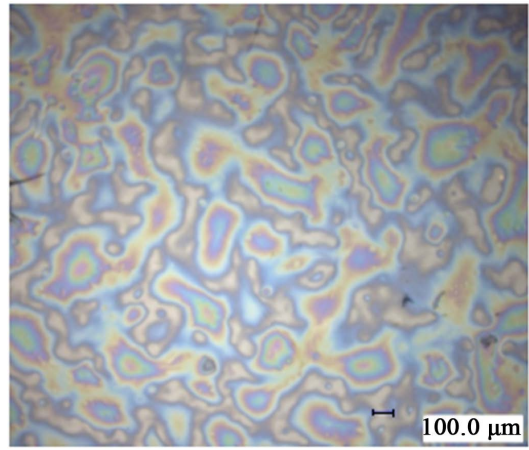

(c)

Figure 4. Microscope image of the surface of a PEDOT:PSS (3 timesprinting, 100×). (a) $80^{\circ} \mathrm{C}$; (b) $90^{\circ} \mathrm{C}$; (c) $100^{\circ} \mathrm{C}$. 
Table 2. The film thickness of PEDOT:PSS at each annealing temperature (3 times printing).

\begin{tabular}{cc}
\hline Temperature $\left[{ }^{\circ} \mathrm{C}\right]$ & Thickness $[\mathrm{nm}]$ \\
\hline 80 & 222.2 \\
90 & 234.4 \\
100 & 181.1 \\
\hline
\end{tabular}

was to improve the homogeneity of a PEDOT:PSS thin film by applying the polar solvent using an inkjet printer. Figure 5 shows changes in the resistivity, according to the number of printing times, when the application method of the polar solvent was changed. The resistivity of a thin film largely decreased when the polar solvent was applied using an inkjet printer. The increase in the resistivity was also small when the number of printing times was four.

Figure 6 shows images of the surfaces of the PEDOT:PSS thin films, observed using a microscope. In this figure, Figure 6(a) shows the film surface obtained when not treated using the polar solvent. In the inkjet method, an aggregation of ink is observed, which is not reported as observed in other film formation methods [23] [28]. It is then considered that in the aggregation of ink, PEDOT molecules are unevenly distributed. Consequently, the formation of a conductive region is hindered. Also, in this figure, Figure 6(b) shows the film surface obtained by spraying the polar solvent on each layer. The unevenly generated aggregates of PEDOT:PSS particles were fractionated and distributed. Figure 6(c) shows the film surface obtained by applying the polar solvent to each layer using an inkjet printer. The number of gaps between aggregates was smaller in Figure $6(\mathrm{c})$ than in Figure 6(b). Since the thin film of Figure 6(c) was smallest in surface roughness $\mathrm{Sa}$, the aggregates of PEDOT:PSS particles were more evenly distributed.

Figure 7 shows the surfaces of the PEDOT:PSS thin films observed using an AFM. In this figure, Figure 7(a) shows the film surface obtained when not using the polar solvent and Figure 7 (b) shows the film surface obtained by spraying the polar solvent onto each layer. When Figure 7(a) was compared with Figure 7 (b), the unevenness on the film surface was larger in Figure 7(b) than in Figure 7(a). This is probably because the polar solvent was not evenly applied to each layer when it was sprayed. Also, in this figure, Figure 7 (c) shows the film surface obtained by applying the polar solvent to each layer using an inkjet printer. As shown in Figure 7(c), the unevenness on the film surface was reduced. Thus, it was revealed that improvement in the homogeneity of the film surface inhibited an increase in the resistivity when the number of printing times was four.

Figure 8 shows changes in the visible light transmittance, according to the number of printing times, when the application method of the polar solvent was changed. The transmittance was improved by applying the polar solvent to each layer. Due to the fractionation of the aggregates of PEDOT:PSS particles, the bi- 


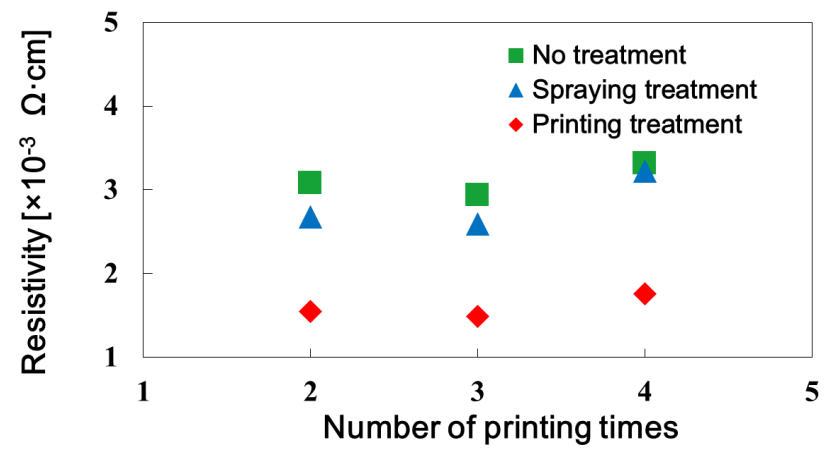

Figure 5. Resistivity as a function of annealing temperature and the number of printing times.

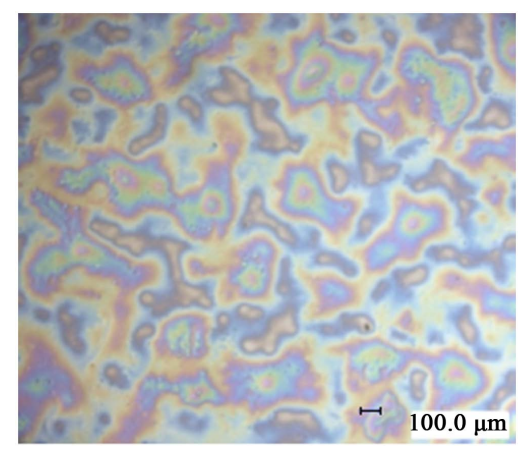

(a)

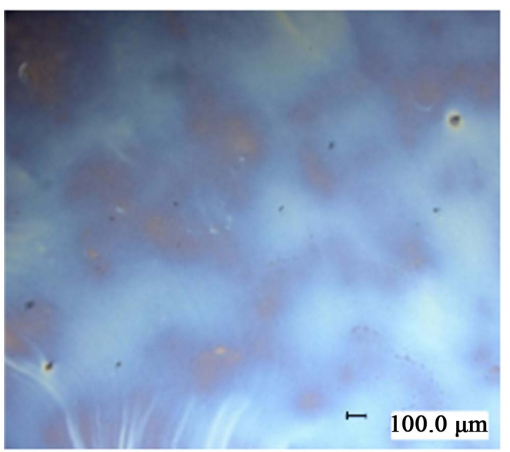

(b)

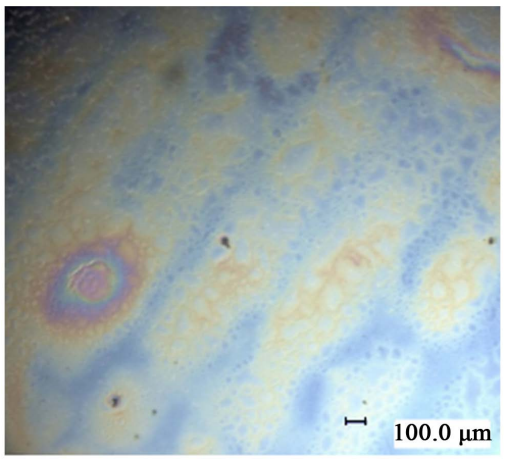

(c)

Figure 6. Microscope image of the surface of a PEDOT:PSS (annealing temperature: $90^{\circ} \mathrm{C}, 3$ times printing, $100 \times$ ). (a) No treatment; (b) Spraying treatment; (c) Printing treatment. 


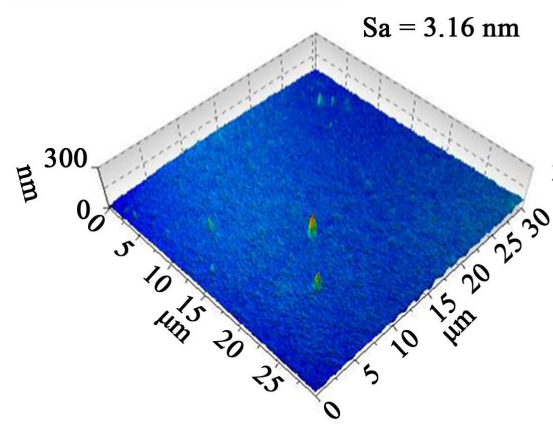

(a)

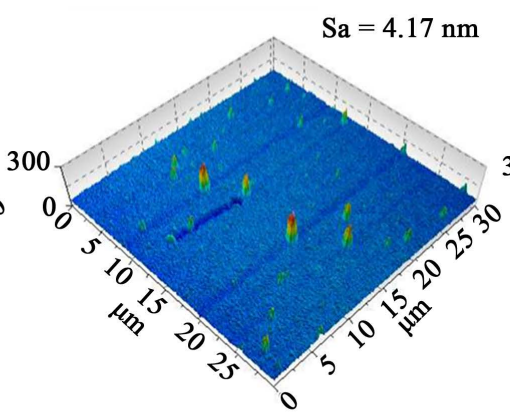

(b)

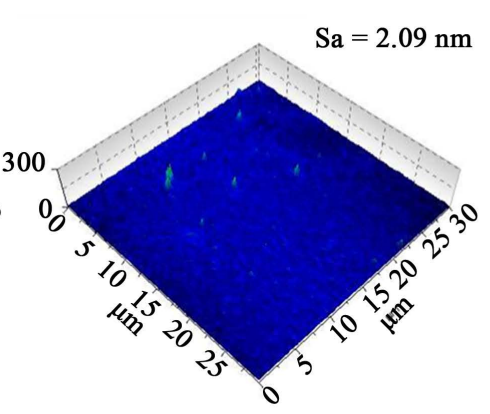

(c)

Figure 7. AFM image of the surface of a PEDOT:PSS (annealing temperature: $90^{\circ} \mathrm{C}, 3$ times printing, $\times 100$ ). (a) No treatment; (b) Spraying treatment; (c) Printing treatment.

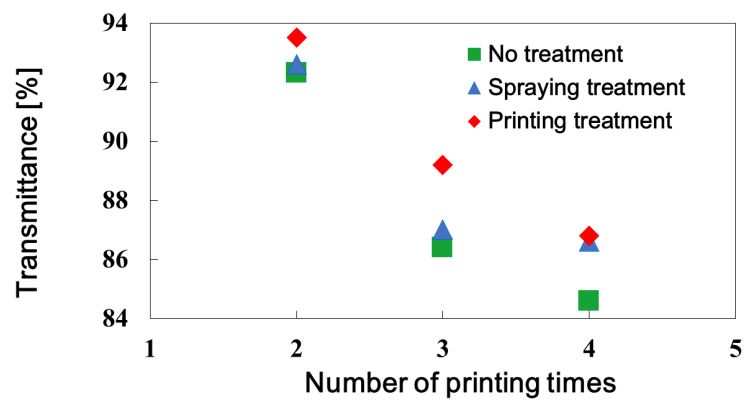

Figure 8.Transmittance as a function of annealing temperature and the number of printing times.

as in the distribution of PEDOT:PSS particles caused by the printing pattern was reduced. Consequently, visible light transmittance increased. By uniformly applying the polar solvent using an inkjet printer, uniformity that could not be obtained by spraying it, the aggregates of PEDOT:PSS particles were fractionated and the surface state of the thin film homogenized. Consequently, visible light transmittance was improved.

\section{Conclusions}

In the present study, PEDOT:PSS was used as a substitute for ITO. A thin film was formed on the plastic-film substrate using an inkjet printer. To further improve the characteristics of the PEDOT:PSS thin film, annealing temperature and polar solvent application methods were examined.

At the annealing temperature of $80^{\circ} \mathrm{C}$, the solvent which decreased conductivity could not be sufficiently removed. At the annealing temperature of $90^{\circ} \mathrm{C}$, the solvent could be sufficiently removed. Consequently, the resistivity was improved. When the annealing temperature was $100^{\circ} \mathrm{C}$, PEDOT:PSS evaporated so film thickness was difficult to control.

When the polar solvent was applied using an inkjet printer, the resistivity decreased and the visible light transmittance increased. Moreover, the fractionation of the aggregates of PEDOT:PSS particles and the homogenization of the film surface were facilitated. When the number of printing times was three, the 
resistivity was low under all conditions. This is because the interface of the thin film increased with the number of printing times. By homogenizing the film surface, increase in the resistivity could be inhibited.

The resistivity and transmittance of a PEDOT:PSS thin film were $1.49 \times 10^{-3}$ $\Omega \cdot \mathrm{cm}$ and $89.2 \%$, respectively. This film was obtained by annealing at $90^{\circ} \mathrm{C}$ for 30 min and applying the polar solvent, using an inkjet printer, between printing operations. The printing was performed three times. However, in comparison with the commonly used ITO thin film, there is room for improvement in the performance.

In the future, we are planning to homogenize the film surface by studying additives and ink composition.

\section{References}

[1] Dinesh, P., Tomas, W., Tham, A. and Jean-Michel, N. (2015) Photovoltaic Performance of AgInSe $\mathrm{S}_{2}$-Conjugated Polymer Hybrid System Bulk Heterojunction Solar Cells. Synthetic Metals, 199, 87-92. https://doi.org/10.1016/j.synthmet.2014.11.015

[2] Dinesh, P., Tomas, W., Tham, A. and Jean-Michel, N. (2015) AgInSe $2 . P C B M . P 3 H T$ Inorganic Organic Blends for Hybrid Bulk Heterojunction Photovoltaics. Synthetic Metals, 200, 102-108. https://doi.org/10.1016/j.synthmet.2015.01.001

[3] Yoon, K.S., Chul, W.J., Jonghee, L., Joo, W.H., Dong, J.L., Siti, A.N.E., Soukyoon, K., Nam, S.C. and Yong, H.K. (2017) Enhanced Electrical Properties of PEDOT:PSS Films Using Solvent Treatment and Its Application to ITO-Free Organic Light-Emitting Diodes. Journal of Luminescence, 187, 221-226. https://doi.org/10.1016/j.jlumin.2017.03.002

[4] Suat, P., Reza, M., Soner, Ö., Volkan, Ş., Yudar, H.H. and Şadan, K. (2017) The Al Doping Effect on the Surface, Optical, Electrical and Nanomechanical Properties of the $\mathrm{ZnO}$ and AZO Thin Films Prepared by RF Sputtering Technique. Vacuum, 141, 210-215. https://doi.org/10.1016/j.vacuum.2017.04.025

[5] Bedi, R.K., Davinder, K. and Dinesh, P. (2010) Effect of Substrate Temperature on the Structural, Optical, and Electrical Properties of Silver-Indium-Selenide Films Prepared by Using Laser Ablation. Journal of the Korean Physical Society, 56, 836841. https://doi.org/10.3938/jkps.56.836

[6] Dinesh, P., Bedi, R.K., Davinder, K. and Ravi, K. (2010) Fabrication of Densely Distributed Silver Indium Selenide Nanorods by Using Ag+ Ion Irradiation. Journal of the Korean Physical Society, 57, 474-479. https://doi.org/10.3938/jkps.57.474

[7] Praloy, M. and Debajyoti, D. (2017) Further Improvements in Conducting and Transparent Properties of ZnO:Ga Films with Perpetual c-Axis Orientation: Materials Optimization and Application in Silicon Solar Cells. Applied Surface Science, 411, 315-320. https://doi.org/10.1016/j.apsusc.2017.03.171

[8] Keunhee, L. and Hyungson, K. (2017) Fabrication and Optimization of Transparent Conductive Films Using Laser Annealing and Picosecond Laser Patterning. Applied Surface Science, 420, 886-895. https://doi.org/10.1016/j.apsusc.2017.05.200

[9] Munkhshur, M., Sinil, L., Taejin, L., Hanshik, C. and Hyomin, J. (2015) A Facile and Eco-Friendly Synthesis of Graphene-Silver Hybrid Materials for Transparent Conductive Films. Ceramics International, 41, 983-989. https://doi.org/10.1016/j.ceramint.2014.09.018

[10] Philipp, M., Kai, C.T., Luca, L., Hans-Joachim, E., Horst, S., Eugen, M. and Chris- 
toph, J.B. (2016) Inkjet Printed Silver Nanowire Percolation Networks as Electrodes for Highly Efficient Semitransparent Organic Solar Cells. Organic Electronics, 38, 139-143. https://doi.org/10.1016/j.orgel.2016.08.006

[11] Oytun, F., Dizman, C., Karatepe, N., Alpturk, O. and Başarır, F. (2017) Preparation of Transparent Conducting Electrode on Polysulfone Film via Multilayer Transfer of Layer-by-Layer Assembled Carbon Nanotubes. Thin Solid Films, 625, 168-176. https://doi.org/10.1016/j.tsf.2017.01.066

[12] Han, S.-H., Kim, B.-J. and Park, J.-S. (2014) Effects of the Corona Pretreatment of PET Substrates on the Properties of Flexible Transparent CNT Electrodes. Thin Solid Films, 572, 73-78. https://doi.org/10.1016/j.tsf.2014.09.066

[13] Xia, Y., Wang, P., He, G., Zhang, M., Shi, S., Liu, Y. and Sun, Z. (2017) Microstructure, Opotoelectrical and Pre-Strain Dependent Electrical Properties of Azo Films on Flexible Glass Substrates for Flexible Electronics. Surface and Coatings Technology, 320, 34-38. https://doi.org/10.1016/j.surfcoat.2017.02.014

[14] Moon, C.-J., Kim, I., Joo, S.-J., Chung, W.-H., Lee, T.-M. and Kim, H.-S. (2017) Flash Light Sintering of Ag Mesh Films for Printed Transparent Conducting Electrode. Thin Solid Films, 629, 60-68. https://doi.org/10.1016/j.tsf.2017.03.049

[15] Perinka, N., Kim, C.H., Kaplanova, M. and Bonnassieux, Y. (2013) Preparation and Characterization of Thin Conductive Polymer Films on the Base of PEDOT:PSS by Ink-Jet Printing. Physics Procedia, 44, 120-129.

https://doi.org/10.1016/j.phpro.2013.04.016

[16] Chen, Y., Lan, W., Wang, J., Zhu, R., Yang, Z., Ding, D., Tang, G., Wang, K., Su, Q. and Xie, E. (2016) Highly Flexible, Transparent, Conductive and Antibacterial Films Made of Spin-Coated Silver Nanowires and a Protective ZnO Layer. Physica E: Low-Dimensional Systems and Nanostructures, 76, 88-94. https://doi.org/10.1016/j.physe.2015.10.009

[17] Park, C.B., Kim, K.M., Lee, J.E., Na, H., Yoo, S.S. and Yang, M.S. (2014) Flexible Electrophoretic Display Driven by Solution-Processed Organic TFT with Highly Stable Bending Feature. Organic Electronics, 15, 3538-3545. https://doi.org/10.1016/j.orgel.2014.09.039

[18] Seo, K.-W., Noh, Y.-J., Na, S.-I. and Kim, H.-K. (2016) Random Mesh-Like Ag Networks Prepared via Self-Assembled Ag Nanoparticles for ITO-Free Flexible Organic Solar Cells. Solar Energy Materials and Solar Cells, 155, 51-59. https://doi.org/10.1016/j.solmat.2016.04.056

[19] Wang, Z., Wang, W., Jiang, Z. and Yu, D. (2017) A Novel and Simple Method of Printing Flexible Conductive Circuits on PET Fabrics. Applied Surface Science, 396, 208-213. https://doi.org/10.1016/j.apsusc.2016.09.155

[20] Jaeheung, H., Jongjang, P., Jewook, H., Donghyun, K., Seungjun, C., Changhee, L. and Yongtaek, H. (2015) Selectively Modulated Inkjet Printing of Highly Conductive and Transparent Foldable Polymer Electrodes for Flexible Polymer LightEmitting Diode Applications. Organic Electronics, 19, 147-156.

https://doi.org/10.1016/j.orgel.2015.01.017

[21] Lai, S., Cosseddu, P., Zucca, A., Loi, A. and Bonfiglio, A. (2017) Combining Inkjet Printing and Chemical Vapor Deposition for Fabricating Low Voltage, Organic Field-Effect Transistors on Flexible Substrates. Thin Solid Films, 631, 124-131. https://doi.org/10.1016/j.tsf.2017.04.021

[22] Cho, C.-L., Kao, H., Chang, L.-C., Wu, Y.-H. and Chiu, H.-C. (2017) Fully InkjetPrinting of Metal-Polymer-Metal Multilayer on a Flexible Liquid Crystal Polymer Substrate. Surface and Coatings Technology, 320, 568-573. 
https://doi.org/10.1016/j.surfcoat.2016.11.004

[23] Nitta, A. and Shimono, K. (2015) Preparation of PDOT:PSS Transparent Conductive Film Using Ink-Jet Printing. Advances in Materials Physics and Chemistry, 5, 467-476. https://doi.org/10.4236/ampc.2015.512047

[24] Nitta, A., Kawahara, K. and Miyata, K. (2016) Characteristics Improvement of PEDOT:PSS Transparent Conductive Film Prepared by Ink-Jet Printing. Advances in Materials Physics and Chemistry, 6, 239-247. https://doi.org/10.4236/ampc.2016.68024

[25] Jönsson, S.K.M., Birgerson, J., Crispin, X., Greczynski, G., Osikowicz, W., van der Gon, A.W.D., Salaneck, W.R. and Fahlman, M. (2003) The Effects of Solvents on the Morphology and Sheet Resistance in Poly(3,4-Ethylenedioxythiophene)-Polystyrenesulfonic Acid (PEDOT-PSS) Films. Synthetic Metals, 139, 1-10. https://doi.org/10.1016/S0379-6779(02)01259-6

[26] Hu, Y. and Okuzaki, H. (2009) Effect of Solvent on PEDOT/PSS Nanometer-Scaled Thin Films: XPS and STEM/AFM Studies. Synthetic Metals, 159, 2225-2228. https://doi.org/10.1016/j.synthmet.2009.07.032

[27] Takano, T., Masunaga, H., Fujiwara, A., Okuzaki, H. and Sasaki, T. (2012) PEDOT Nanocrystal in Highly Conductive PEDOT:PSS Polymer Films. Macromolecules, 45, 3859-3865. https://doi.org/10.1021/ma300120g

[28] Oko, A., Swerin, A., Brandner, B.D., Bugner, D., Cook, W. and Claesson, P.M. (2014) Aggregation of Inkjet Ink Components by $\mathrm{Ca}$ and $\mathrm{Mg}$ Ions in Relation to Colorant Pigment Distribution in Paper. Colloids and Surfaces A: Physicochemical and Engineering Aspects, 456, 92-99. https://doi.org/10.1016/j.colsurfa.2014.05.023

Submit or recommend next manuscript to SCIRP and we will provide best service for you:

Accepting pre-submission inquiries through Email, Facebook, LinkedIn, Twitter, etc. A wide selection of journals (inclusive of 9 subjects, more than 200 journals)

Providing 24-hour high-quality service

User-friendly online submission system

Fair and swift peer-review system

Efficient typesetting and proofreading procedure

Display of the result of downloads and visits, as well as the number of cited articles

Maximum dissemination of your research work

Submit your manuscript at: http://papersubmission.scirp.org/

Or contact ampc@scirp.org 